\title{
Distribution of fluoroquinolone resistance determinants in Carbapenem-resistant Klebsiella pneumoniae clinical isolates associated with bloodstream infections in China
}

Qing Zhan ${ }^{1+}$, Yanlei Xu ${ }^{1 \dagger}$, Bingjie Wang ${ }^{2}$, Jingyi Yư ${ }^{3}$, Xiaofei Shen ${ }^{4}, \mathrm{Li} \mathrm{Liu}^{3}$, Xingwei Cao ${ }^{1}$, Yinjuan Guo ${ }^{2,5}$ and Fangyou $\mathrm{Yu}^{2,5^{*}}$

\begin{abstract}
Background: The rate of fluoroquinolone (FQ) resistance among carbapenem-resistant Klebsiella pneumoniae (CRKP) is high. The present study aimed to investigate the distribution of fluoroquinolone resistance determinants in clinical CRKP isolates associated with bloodstream infections (BSIs).

Results: A total of 149 BSI-associated clinical CRKP isolates collected from 11 Chinese teaching hospitals from 2015 to 2018 were investigated for the prevalence of fluoroquinolone resistance determinants, including plasmid-mediated quinolone resistance (PMQR) genes and spontaneous mutations in the quinolone resistance-determining regions (QRDRs) of the gyrA and parC genes. Among these 149 clinical CRKP isolates, 117 (78.5\%) exhibited resistance to ciprofloxacin. The GyrA substitutions (Ser83 $\rightarrow$ Ile/Phe) and (Asp87 $\rightarrow$ Gly/Ala) were found among 112 (75.2\%) of 149 isolates, while the substitution (Ser80 $\rightarrow$ Ile) of ParC was found in 111 (74.5\%) of the 149 isolates. In total, 70.5\% (105/ 149) of the CRKP isolates had at least two mutations within gyrA as well as a third mutation in parC. No mutations in the QRDRs were found in 31 ciprofloxacin susceptible CRKP isolates. Eighty-nine (56.9\%) of 149 were found to carry PMQR genes including anrS1 (43.0\%), aac(6')-lb-cr (16.1\%), anrB4 (6.0\%), anrB2 (2.7\%), and anrB1 (1.3\%). Nine isolates contained two or more PMQR genes, with one carrying four [aac $\left(6^{\prime}\right)-1 b-c r$, anr-S1, anrB2, and anrB4]. The co-existence rate of PMQR determinants and mutations in the QRDRs of gyrA and parC reached 68.5\% (61/89). Seventy-four (83.1\%, 74/89) PMQR-positive isolates harbored extended-spectrum beta-lactamase (ESBL)-encoding genes. Multilocus sequence typing (MLST) analysis demonstrated that the ST11 was the most prevalent STs in our study.
\end{abstract}

\footnotetext{
*Correspondence: wzjxyfy@163.com

${ }^{\dagger}$ Qing Zhan and Yanlei Xu contributed equally to this work.

${ }^{2}$ Department of Clinical Laboratory Medicine, Shanghai Pulmonary Hospital,

Tongji University School of Medicine, Shanghai 200082, P. R. China

${ }^{5}$ Shanghai Key Laboratory of Tuberculosis, Shanghai Pulmonary Hospital,

Tongji University School of Medicine, Shanghai 200082, P. R. China

Full list of author information is available at the end of the article
} 
Conclusions: Mutations in the QRDRs of gyrA and parC were the key factors leading to the high prevalence of fluoroquinolone resistance among BSI-associated CRKP. The co-existence of PMQR genes and mutations in the QRDRs can increase the resistance level of CRKP to fluoroquinolones in clinical settings. ST11 CRKP isolates with identical QRDR substitution patterns were found throughout hospitals in China.

Keywords: CRKP, Bloodstream infections, Fluoroquinolones, PMQR, QRDR, ST11

\section{Introduction}

Klebsiella pneumoniae is a commonly detected pathogen in hospital settings, causing nosocomial and communityacquired infections in the lung, urinary tract, surgical sites, soft tissue infections and the bloodstream [1]. CRKP has emerged as a worldwide problem, posing major challenges for its clinical management and public health, through its ability to cause severe and untreatable infections in otherwise healthy individuals [2,3]. In particular, BSIs caused by CRKP is associated with high mortality due to the ineffectiveness of antibacterials used to treat them [4]. CRKP usually shows high levels of resistance to many types of antibiotics [5]. The optimal treatment options for CRKP infections are not well defined. They currently include the use of older agents either as monotherapy or in combination with drugs such as fluoroquinolones (FQs) [6, 7].

FQs are important synthetic antimicrobial agents extensively used in clinical and veterinary medicine. They exhibit broad-spectrum activity against a wide of important clinical pathogens and exhibit excellent tissue penetration [8-10]. To reduce the use of carbapenems, FQs have been proposed as first-choice alternatives in the treatment of FQ-susceptible, ESBL-producing enterobacterial organisms in pyelonephritis [11]. Carbapenems with FQ are also used to treat carbapenem nonsusceptible K. pneumoniae infections [12, 13]. However, resistance to FQs has increased rapidly due to their overuse, thereby limiting the available treatment options or leading to treatment failure [14, 15]. FQs target DNA gyrase A and topoisomerase IV, which are encoded by gyrA and parC, respectively. The biological mechanisms of resistance to FQs include impermeability, active efflux, target modification, and antibiotic neutralization. Two major mechanisms involved in the development of quinolone resistance are the acquisition of plasmidmediated quinolone resistance (PMQR) genes [such as $a a c\left(6^{\prime}\right)-I b-c r$ and $\left.q n r\right]$ and spontaneous mutations in quinolone resistance-determining regions (QRDRs) of gyrA and parC [16-18]. PMQR genes have recently been shown to confer low-level resistance to $\mathrm{FQs}$ and can be horizontally transferred [19]. The co-carriage of mutations in QRDRs and PMQR genes has been reported in clinical isolates of Enterobacteriaceae exhibiting highlevel quinolone resistance $[18,20,21]$. Alterations in both $\operatorname{gyr} A$ and $\operatorname{parC}$ often confer high-level resistance and are reported more frequently than those in $\operatorname{gyr} B$ or parE [16]. However, relatively few studies have assessed the prevalence of $\mathrm{PMQR}$ determinants and the diversity of DNA gyrase and topoisomerase IV mutations in clinical isolates of CRKP associated with BSIs in China [14, 22]. Accordingly, the current study aimed to investigate the prevalence, molecular characteristics, and distribution of PMQR determinants and mutations in the QRDRs of gyrA and parC BSI-associated clinical CRKP isolates from 11 hospitals in China.

\section{Materials and methods \\ Collection and identification of clinical $K$. pneumoniae isolates}

From April 2015 to November 2018, a total of 149 CRKP isolates were cultured from the blood of patients with BSIs in 11 hospitals in eight provinces of China, including Zhejiang $(n=22)$, Fujian $(n=9)$, Shandong $(n=$ 26), Hubei $(n=10)$, Henan $(n=16)$, Shanghai $(n=18)$, Jiangxi $(n=40)$, and Hunan $(n=8)$. These K. pneumoniae isolates were identified by Gram-staining and a VITEK-2 automated platform (bioMérieux, Marcy l'Etoile, France) according to the manufacturer's instructions, as well as by additional biochemical testing. CRKP isolates were selected based on resistance to imipenem or meropenem according to Clinical and Laboratory Standards Institute (CLSI) guidelines [23]. Escherichia coli ATCC25922 and Pseudomonas aeruginosa ATCC27853 were used as control isolates for the identification and antimicrobial susceptibility testing of bacterial clinical isolates.

\section{Antimicrobial susceptibility testing}

MICs of carbapenem (imipenem, meropenem), fluoroquinolones (ciprofloxacin), aminoglycosides (amikacin and gentamicin), $\beta$-lactams/ $\beta$-lactamase inhibitor complexes (ceftazidime-avibactam and piperacillin-tazobactam), cephalosporins (ceftazidime, cefepime, cefotaxime, and cefoxitin), folate metabolic pathway inhibitors (sulfamethoxazole), polymyxin $\mathrm{B}$, tetracyclines (tigecycline, minocycline, and tetracycline), and monocyclic $\beta$-lactam (aztreonam) were determined by the broth microdilution method, according to Clinical and Laboratory Standards Institute (CLSI) guidelines [23]. The results were interpreted according to CLSI breakpoints. E. coli ATCC 25922 was used as a control isolate for antimicrobial susceptibility testing. 


\section{PCR detection and DNA sequence analyses of QRDR and PMQR}

Genomic DNA (gDNA) of the 149 CRKP isolates was extracted using the Ezup Column Bacteria Genomic DNA Purification Kits (Sangon Biotech, Shanghai, China) according to the manufacturer's instructions. The Qubit and Nanodrop were used to determine the concentrations and purity of the extracted gDNA. The nucleotide mutations in the QRDRs of gyrA and parC were further tested by PCR and nucleotide sequencing using previously primers described [24]. Nucleotide mutations were identified based on the available nucleotide sequences of gyrA and parC genes of $K$. pneumoniae ATCC 13833. Sequence alignment and analysis were performed online using the BLAST program (http:// www.ncbi.nlm.nih.gov). Plasmids were extracted from the 149 CRKP isolates using a Plasmid Midi Kit (Qiagen, Germany), and all the isolates were screened for the presence of the PMQR genes, including $q n r A$, qnrB, $q n r S$, qepA, and $a a c\left(6^{\prime}\right)-I b-c r$, by PCR and DNA sequencing [25].

\section{The detection of carbapenem resistance genes and ESBLs-encoding genes}

Carbapenemase genes $\left(b l a_{K P C}, b l a_{I M P}, b l a_{V I M}, b l a_{N D M}\right.$, $\left.b l a_{O X A-48}\right)$ and ESBLs-producing genes (bla $a_{C T X-M}$, $\left.b l a_{S H V}, b l a_{T E M}\right)$ of all CRKP isolates were detected by PCR using gene-specific primers for each one, as previously reported $[26,27]$.

\section{Multilocus sequence typing}

Multilocus sequence typing (MLST) was performed on all 149 CRKP isolates using primers targeting seven standard housekeeping genes (gapA, infB, mdh, pgi, phoE, rpoB and ton $B$ ) listed on the PubMLST website (http://www.pasteur.fr/recherche/genopole/PF8/mlst/ Kpneumoniae.html) according to previously published methods, and the sequence types (STs) were determined using the MLST database [28].

\section{Statistical analysis}

The data obtained for all CRKP isolates harboring different FQs resistance mechanisms were analyzed by SPSS software (version 20, IBM SPSS Statistics). The chisquare test was used for categorical variables. $P$-values < 0.05 were considered significant.

All the experiments were carried out following the relevant guidelines and regulations.

\section{Results}

\section{The resistance of CRKP isolates to ciprofloxacin}

Among 149 K. pneumoniae isolates, 117 (79.4\%) exhibited resistance to ciprofloxacin, whereas only 31 (20.8\%) showed susceptibility to ciprofloxacin (MICs of $\leqq 1 \mu \mathrm{g} / \mathrm{ml}$ ), and one showed intermediate resistance to ciprofloxacin (MIC of $2 \mu \mathrm{g} / \mathrm{ml}$ ).

\section{The prevalence of mutations in the QRDRs of $g y r A$ and parC among clinical CRKP isolates}

Among the 149 CRKP isolates, the nucleotide mutations in QRDRs were detected in 112 (75.2\%) isolates. Substitutions of QRDRs were observed at position 83 (102 isolates with Ser83 $\rightarrow$ IIe and 10 isolates with Ser83 $\rightarrow$ Phe) and position 87 (97 isolates with Asp87 $\rightarrow$ Gly and 10 isolates with Asp87 $\rightarrow$ Ala) of GyrA. The substitutions of Ser83 $\rightarrow$ Phe and Asp87 $\rightarrow$ Ala substitutions co-existed in 10 ciprofloxacin-resistant isolates. Mutations in parC were only found at position 80 (Ser80 $\rightarrow$ IIe) among 111 (74.5\%) of the 149 isolates (Table 1$)$. No gyrB or parE mutations were observed in any of the CRKP isolates.

There were 105 ciprofloxacin resistant CRKP isolates co-carried at least two mutations within $g y r A$ and one in parC. And the 105 isolates with multiple mutations in QRDRs were distributed in 8 provinces, including Jiangxi $(n=38)$, Shandong $(n=10)$, Hubei $(n=7)$, Henan $(n=$ 13), Shanghai $(n=16)$, Zhejiang $(n=9)$, Fujian $(n=9)$, and Hunan $(n=3)$.

\section{The prevalence of PMQR determinants among the 149 CRKP isolates}

Among the 149 CRKP isolates tested, 89 (56.9\%, 89/149) including $73.0 \%(65 / 89)$ of ciprofloxacin-resistant isolates were found to carry at least one PMQR gene, including qnrS1 (71.9\%, 64/89), aac(6')-Ib-cr (27.0\%, 24/ 89), qnrB4 (10.1\%, 9/89), qnrB2 (4.5\%, 4/89) and qnrB1 $(3.4 \%, 3 / 89)$. Nine isolates harbored two or more PMQR genes (Table 1). The qur genes $(59.7 \%, 74 / 149)$ were the major PMQR determinants and included 2 qnr families ( $q n r B$ and $q n r S$ ). Twenty-eight (31.5\%) of the 89 isolates with PMQR genes, 4 of which were resistant to ciprofloxacin, did not have mutations in the QRDRs. Among the 31 ciprofloxacin-susceptible isolates, 8 with no PMQR genes had ciprofloxacin MICs of $\leq 0.25 \mu \mathrm{g} / \mathrm{ml}$, which were lower than those found for the 23 isolates carrying PMQR genes (Table 2).

The 89 isolates carrying PMQR genes were distributed in 8 provinces, including Jiangxi $(n=29)$, Shandong $(n=$ 13), Hubei $(n=3)$, Henan $(n=8)$, Shanghai $(n=10)$, Zhejiang $(n=16)$, Fujian $(n=8)$, and Hunan $(n=2)$. The 66 isolates harboring $q n r$ family genes were mainly distributed in Jiangxi and Zhejiang and 14 with $a a c\left(6^{\prime}\right)-I b$ cr were found mainly in Shandong.

The co-existence of PMQR and mutations in QRDRs The co-existence rate of PMQR determinants and mutations in the QRDRs of $g y r A$ and parC were relatively high $(68.5 \%, 61 / 89)$, with 60 being resistant to ciprofloxacin, and one showing intermediary resistance to 
Table 1 Patterns and distribution of GyrA and ParC substitutions and PMQR in 149 clinical CRKP isolates

\begin{tabular}{|c|c|c|c|c|}
\hline CIP (MIC) & Mutation & Carrying PMQR (frequency) & Frequency & MLST (number of isolates) \\
\hline$S$ & No substitution & $\begin{array}{l}\operatorname{aac}\left(6^{\prime}\right)-\operatorname{lb}-c r(12) \\
\text { anrS1(9); anrB1 (1); } \\
\operatorname{aac}\left(6^{\prime}\right)-\operatorname{lb}-c r, \text { anrS1 (1); } \\
\operatorname{aac}\left(6^{\prime}\right)-\operatorname{lb}-c r, \text { anrS1, qnrB4 (1) }\end{array}$ & 31 & $\begin{array}{l}\text { ST107 (1); ST1319 (2); ST2390 (1); ST290 (7); ST307 (3); } \\
\text { ST35 (2); ST37 (1); ST375 (1); ST45 (12); ST462 (1) }\end{array}$ \\
\hline । & ParC-80l; GyrA-83l; GyrA-87G & gnrS1 (1) & 1 & ST11 (1) \\
\hline $\mathrm{R}$ & No substitution & $\begin{array}{l}\operatorname{aac}\left(6^{\prime}\right)-1 b-c r(1) ; \\
\text { anrS1(1); anrB4 (1); } \\
\text { aac(6')-lb-cr, anrS1 (1); } \\
\text { aac }\left(6^{\prime}\right)-\mid l b-c r, \text { anrS1, anrB2 (1) }\end{array}$ & 6 & ST1692 (2); ST290 (1); ST290 (1); ST2236 (1) \\
\hline $\mathrm{R}$ & ParC-80I; GyrA-83F; GyrA-87A & - & 4 & ST15 \\
\hline $\mathrm{R}$ & ParC-80l; GyrA-83F; GyrA-87A & $\begin{array}{l}\operatorname{aac}\left(6^{\prime}\right)-\operatorname{lb}-c r(2) \\
\operatorname{anrB4}(2) \text { : } \\
\operatorname{aac}\left(6^{\prime}\right)-1 b-c r, \text { anrS1, anrB1 (1); } \\
\operatorname{aac}\left(6^{\prime}\right)-1 b-c r, \text { anrB2 (1) }\end{array}$ & 6 & ST15 (4); ST2237 (2) \\
\hline $\mathrm{R}$ & ParC-80l; GyrA-83l; GyrA-87G & - & 47 & ST11 (47) \\
\hline $\mathrm{R}$ & ParC-80l; GyrA-83l; GyrA-87G & $\begin{array}{l}\text { anrS1 (44); anrB4 (3); } \\
\operatorname{aac}\left(6^{\prime}\right)-1 b-c r, \operatorname{anrB1} \text {, anrB4 (1) }\end{array}$ & 48 & ST11 (48) \\
\hline $\mathrm{R}$ & GyrA-831; GyrA-87G & qnrS1 (1) & 1 & ST11 \\
\hline $\mathrm{R}$ & ParC-80l; GyrA-83| & $\begin{array}{l}\operatorname{aac}\left(6^{\prime}\right)-\operatorname{lb}-c r(1) \text {; anrS1 (2); } \\
\operatorname{aac}\left(6^{\prime}\right)-1 b-c r \text {, anrS1, anrB2, anrB4 (1) } \\
\operatorname{aac}\left(6^{\prime}\right)-1 b-c r, \text { anrB2 (1) }\end{array}$ & 5 & ST438 (2); ST485 (1); ST11 (1); ST395 (1) \\
\hline
\end{tabular}

CIP ciprofloxacin, MIC minimum inhibitory concentration, $R$ resistance, I intermediate, $S$ sensitive, $P M Q R$ plasmid-mediated quinolone resistance, $C R K P$ carbapenemresistant Klebsiella pneumoniae

ciprofloxacin. The patterns of co-carrying of PMQR and mutations in QRDRs could be found in Table 1, Mainly 45 (73.7\%) carried qnrS1 and mutations in gyrA $($ Ser83 $\rightarrow$ IIe, Asp $87 \rightarrow$ Gly) and parC $($ Ser80 $\rightarrow$ IIe). These 61 isolates were distributed in 7 provinces, including Jiangxi $(n=29)$, Hubei $(n=3)$, Henan $(n=$ 6), Shanghai $(n=8)$, Zhejiang $(n=6)$, Fujian $(n=8)$, and Hunan $(n=1)$.

Molecular characteristics of the 149 clinical CRKP isolates Six STs were identified among 112 CRKP isolates harboring mutations in the QRDRs of $\operatorname{gyr} A$ and parC. ST11 was the most prevalent ST $(86.6 \%, 97 / 112)$, followed by ST15 (7.1\%, 8/112), ST2237 (1.8\%, 2/112), and ST438 $(1.8 \%, 2 / 112)$. ST485 and ST395 were each found in only one isolate (Table 1).

Ninety-five ST11 CRKP isolates with identical mutations in the QRDRs were distributed in 8 provinces, including Jiangxi $(n=38)$, Shandong $(n=10)$, Hubei $(n=$
7), Henan $(n=10)$, Shanghai $(n=15)$, Zhejiang $(n=3)$, Fujian $(n=9)$, and Hunan $(n=3)$.

Carbapenem resistance genes profiles, and antimicrobial resistance among PMQR-positive and PMQR-negative CRKP isolates

Among the 89 PMQR-positive CRKP isolates, $b a_{\mathrm{KPC}-2}$ (61 isolates) was the most frequently identified gene, followed by $b l a_{\mathrm{NDM}-5}$ (18 isolates), bla $a_{\mathrm{NDM}-1}$ (17 isolates), and $b a_{\mathrm{IMP}-4}$ ( 1 isolate). Among the 60 PMQRnegative CPKP isolates, $b l a_{\mathrm{KPC}-2}$ (53 isolates) was the most frequently detected gene, followed by $b l a_{\mathrm{NDM}-5}$ (4 isolates), $b l a_{\mathrm{NDM}-1}$ (4 isolates), and $b l a_{\mathrm{IMP}-30}$ (3 isolates). Compared with the PMQR-negative isolates, PMQRpositive isolates harbored fewer $b l a_{\mathrm{KPC}}$ genes but more $b l a_{\text {NDM }}$ genes $(p<0.01)$ (Table 3$)$.

Among the 149 CRKP isolates, PMQR-positive isolates were more sensitive to gentamicin and amikacin but had higher resistance rates to ceftazidime/avibactam,

Table 2 The role of PMQR in 31 FQ-sensitive CRKP isolates

\begin{tabular}{|c|c|c|c|}
\hline Number of isolates & Carrying PMQR (frequency) & Mutation in QRDRs & CIP MIC $(\mu \mathrm{g} / \mathrm{mL})$ \\
\hline 8 & - & No substitution & $\leq 0.25$ (8 isolates) \\
\hline 23 & 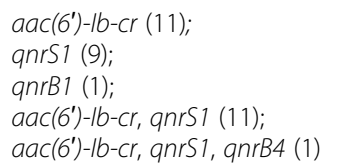 & No substitution & $\begin{array}{l}0.5 \text { (10 isolates) } \\
1 \text { ( } 1 \text { isolate) } \\
\leq 0.25 \text { ( } 12 \text { isolates) }\end{array}$ \\
\hline
\end{tabular}


Table 3 Antibiotic resistance gene profiles and antimicrobial resistance profiling in PMQR-positive and PMQR-negative isolates

\begin{tabular}{|c|c|c|c|c|c|c|}
\hline \multicolumn{2}{|c|}{ Antimicrobial resistance profiling } & \multicolumn{4}{|l|}{ CRKPs $(n=149)$} & \multirow[t]{2}{*}{$P$-values } \\
\hline & & $\mathrm{PMQR}+(n=89)$ & $\%$ & PMQR- $(n=60)$ & $\%$ & \\
\hline \multirow[t]{5}{*}{ Carbapenem resistance genes } & $b l a_{\mathrm{NDM}}$ & 26 & 29.2 & 3 & 5 & $<0.01$ \\
\hline & $b l a_{\mathrm{KPC}}$ & 51 & 57.3 & 48 & 80 & $<0.01$ \\
\hline & $b / a_{I M P}$ & 0 & 0 & 3 & 5 & $>0.05$ \\
\hline & $b l a_{\mathrm{NDM}}+b l a_{\mathrm{KPC}}$ & 9 & 10.1 & 5 & 8.3 & $>0.05$ \\
\hline & $b / a_{\mathrm{IMP}}+b / a_{\mathrm{KPC}}$ & 1 & 1.1 & 0 & 0 & 1 \\
\hline \multirow[t]{3}{*}{ ESBL genes } & $b l a_{\mathrm{CTX}-\mathrm{M}}$ & 41 & 46.1 & 31 & 51.7 & $>0.05$ \\
\hline & $b l a_{\mathrm{SHV}}$ & 5 & 5.6 & 5 & 8.3 & $>0.05$ \\
\hline & $b l a_{\mathrm{CTX}-\mathrm{M}}+b / a_{\mathrm{SHV}}$ & 26 & 29.2 & 21 & 35 & $>0.05$ \\
\hline \multirow[t]{17}{*}{ Antimicrobial } & Imipenem & 88 & 98.9 & 58 & 96.7 & $>0.05$ \\
\hline & Meropenem & 89 & 100.0 & 60 & 100 & $>0.05$ \\
\hline & Cefoxitin & 86 & 96.6 & 58 & 96.7 & $>0.05$ \\
\hline & Cefotaxime & 88 & 98.9 & 60 & 100 & $>0.05$ \\
\hline & Cefepime & 88 & 98.9 & 59 & 98.3 & $>0.05$ \\
\hline & Ceftazidime & 87 & 97.8 & 59 & 98.3 & $>0.05$ \\
\hline & Aztreonam & 79 & 88.8 & 58 & 96.7 & $>0.05$ \\
\hline & Gentamicin & 52 & 58.4 & 45 & 75.0 & $<0.05$ \\
\hline & Amikacin & 35 & 39.3 & 40 & 66.7 & $<0.01$ \\
\hline & Ceftazidime/ avibactam & 28 & 31.5 & 9 & 15.0 & $<0.05$ \\
\hline & Polymyxin B & 2 & 2.2 & 3 & 5.0 & $>0.05$ \\
\hline & Tigecycline & 4 & 4.5 & 0 & 0 & $>0.05$ \\
\hline & Piperacillin/ tazobactam & 80 & 89.9 & 54 & 90.0 & $>0.05$ \\
\hline & Ciprofloxacin & 65 & 73.0 & 52 & 86.7 & $<0.05$ \\
\hline & Tetracycline & 68 & 76.4 & 12 & 20.0 & $<0.01$ \\
\hline & Minocycline & 52 & 58.4 & 12 & 20.0 & $<0.01$ \\
\hline & Sulfamethoxazole & 65 & 73.0 & 17 & 28.3 & $<0.01$ \\
\hline
\end{tabular}

PMQR+: Represents CRKP isolates with PMQR genes

PMQR-: Represents CRKP isolates without PMQR genes

+: Represents one CRKP isolate harboring two antibiotic-resistance genes simultaneously

$P<0.05$ was considered statistically significant

$P M Q R$ plasmid-mediated quinolone resistance, CRKP carbapenem-resistant Klebsiella pneumoniae, ESBL extended-spectrum beta-lactamase

tetracycline, minocycline, and sulfamethoxazole compared with PMQR-negative isolates $(p<0.01)$. PMQRnegative isolates were more resistant to ciprofloxacin due to mutations in QRDRs $(p<0.05)$.

\section{Discussion}

The emergence of CRKP over the past few decades has posed an increasing threat to public health worldwide [2]. FQs have broad-spectrum antimicrobial activities against both Gram-positive and Gram-negative bacteria and have been widely used since the 1980s [29]. In our study, we collected a total of 149 CRKP isolates from clinical patients with BSIs from 11 teaching hospitals across China, and 78.5\% (117/149) of the isolates exhibited resistance to ciprofloxacin. Notably, most of the CRKP isolates tested showed high-level resistance to ciprofloxacin and were distributed in eight provinces surveyed in China.

The most prevalent mechanism underlying FQ resistance in K. pneumoniae involves mutations in QRDRs. Resistance to $\mathrm{FQs}$ is associated with alterations in the GyrA subunit of DNA gyrase and the ParC subunit of DNA topoisomerase IV [30]. Additionally, in 1996, Georgiou et al. reported that some key mutations identified in $g y r A$ and $\operatorname{parC}$ were associated with high-level resistance to ciprofloxacin [31]. In our study, among the 117 ciprofloxacin-resistant isolates, $94.8 \%$ had mutations in QRDRs, and all the high levels of resistance (MICs of 16 and 32) were associated with QRDR mutations. Ser80 $\rightarrow$ IIe in ParC $(111 / 149,74.5 \%)$ was the most common substitution among the 149 CRKP isolates, while Ser $83 \rightarrow$ Ile/Phe and Asp87 $\rightarrow$ Ala/Gly in GyrA were also frequently observed. These GyrA and ParC 
substitutions observed in this study have already been reported [16]. None of the CRKP isolates harboring mutations in QRDRs were sensitive to ciprofloxacin, suggesting that mutations in QRDRs are the primary cause of FQ resistance. Multiple amino acid substitutions in QRDRs are needed for the acquisition of high-level resistance to FQs [9, 32]. In the present study, isolates possessing double or more amino acid substitutions in QRDRs were highly prevalent, with 105 FQ-resistant CRKP isolates exhibiting at least two mutations within gyrA as well as a third mutation in $\operatorname{parC}$. The rate of FQs resistance in $K$. pneumoniae has become very high in some parts of Europe, CRKP usually belongs to several genetic lineages, such as the high prevalence of ST11 [33]. Also, ST11 CRKP has become the dominant clone in many China provinces [34, 35]. Similarly, ST11 was the most frequently identified ST among the 117 ciprofloxacin-resistant isolates in our study. Almost all the ST11 isolates had identical mutation patterns in QRDRs and were detected in 8 provinces in China, indicative of wide distribution. This suggests that these isolates, harboring the same FQ resistance gene profiles, may have disseminated vertically by clonal and multiclonal expansion. Similar patterns of the mutation have been reported in clinical Enterobacteriaceae isolated in Warsaw, Poland, but not such large accumulations in clinical CRKP isolates [22].

PMQR determinants ( $q n r$ and $a a c\left(6^{\prime}\right)-I b-c r$ genes) have been found in plasmids and are generally thought to confer only low levels of FQ resistance [36]. A higher rate of PMQR (59.7\% 89/149) was detected with CRKP in the current study, which may explain the predominance of PMQR genes among the $K$. pneumoniae isolates [22]. The most frequently detected PMQR gene among all the isolates was $q n r S 1$, followed by $a a c\left(6^{\prime}\right)-I b-c r$, $q n r B 4$, qnrB2, and qnrB1, which was not consistent with the results of previous Muggeo et.al results that reported $a a c\left(6^{\prime}\right)-I b-c r$ dominance [13]. Nine isolates contained two or more PMQR genes, 1 of which carried four PMQR genes ( $a a c\left(6^{\prime}\right)-I b-c r, q n r-S 1, q n r B 2$, qnrB4). To the best of our knowledge, this is the first study to report the co-existence of four PMQR genes $\left(a a c\left(6^{\prime}\right)-I b\right.$ $c r$, qnr-S1, qnrB2, qnrB4) in CRKP. Among the 31 fluoroquinolone-sensitive CRKP isolates in our study, those positive for PMQR had higher MIC values than their PMQR-negative counterparts, suggesting that PMQR can indeed mediate low levels of drug resistance or increase the MICs of fluoroquinolone-sensitive isolates. Notably, 4 ciprofloxacin-resistant isolates investigated in the present study had no amino acid substitutions in their QRDRs, but all of them had at least one PMQR gene, and all showed considerable resistance levels to FQs (ciprofloxacin MICs of $8 \mu \mathrm{g} / \mathrm{L}$ ) by possessing wild-type gyrA and parC. This suggests that PMQR can also mediate drug resistance, although the MIC value was not as high as that seen with some of the CRKP isolates harboring mutations in QRDRs (30 with ciprofloxacin MICs of $16 \mu \mathrm{g} / \mathrm{ml}, 14$ with ciprofloxacin MICs of $32 \mu \mathrm{g} / \mathrm{ml})$. Remarkably, in the present study, 1 ciprofloxacin-resistant isolate had no PMQR genes or mutations in QRDRs. We speculate that, in addition to the PMQR genes, other undetected mechanisms may be involved in conferring increased resistance, such as altered permeability or the presence of efflux pump systems.

Nagasaka et al. reported that cephalosporin-resistant K. pneumoniae isolates, including those producing ESBL, tend to display resistance to FQs [22]. Additionally, mutations in double-serine residues have often been observed in isolates of the major international STs of ESBL-producing K. pneumonia (gyrA Ser83 $\rightarrow$ Phe/Ile; parC Ser80 $\rightarrow$ Ile) [9].

In conclusion, we characterized 149 BSI-associated clinical CRKP isolates from 11 hospitals located in 8 provinces of China and found that PMQR genes and mutations in QRDRs were highly prevalent. Mutations in the QRDRs of gyrA and parC were key factors underlying FQ resistance in CRKP, while PMQR genes could also increase the level of FQ resistance in the CRKP isolates. Furthermore, the co-existence of PMQR genes and mutations in QRDRs found to be common in this study, led to high levels of FQ resistance. ST11 was the most prevalent ST, while ST11 isolates with identical resistance mechanisms (mutations in QRDRs) were distributed across the eight provinces we investigated, highlighting the need to remain vigilant to prevent its further spread. Additionally, antibiotics, especially quinolones, should be used reasonably in the treatment of clinical CRKP infections.

\section{Acknowledgements}

The authors are grateful to the Department of Clinical Laboratory Medicine, Shanghai Pulmonary Hospital.

\section{Authors' contributions}

$\mathrm{QZ}, \mathrm{XS}, \mathrm{YX}, \mathrm{LL}, J \mathrm{~J}, \mathrm{XC}$, and $\mathrm{YG}$ isolated the bacteria and performed laboratory measurements. QZ and YX collated and analyzed the data. QZ drafted the article. FY made substantial contributions to the study conception and design. BW critically reviewed the manuscript. All the authors read and approved the final version of the manuscript.

\section{Funding}

This study was supported by grants from Shanghai Pulmonary Hospital 2021 Development of Discipline-Department of Clinical Laboratory Medicine.

\section{Availability of data and materials}

The datasets used during the current study are available from the corresponding author upon reasonable request. Most of the data is included in this article. The sequencing data were deposited in GenBank MZ242266MZ242286. 


\section{Declarations}

\section{Ethics approval and consent to participate}

Written informed consent was obtained from all the patients involved in this study. The study was approved by the Ethics Committee of the Shanghai Pulmonary Hospital of Tongji University School of Medicine. All experiments strictly adhered to the guidelines of the Ethics Committee of the Shanghai Pulmonary Hospital of Tongji University School of Medicine.

\section{Consent for publication}

Not applicable.

\section{Competing interests}

All authors declare that they have no conflict of interest in this work.

\section{Author details}

'Jiangxi Provincial Key Laboratory of Preventive Medicine, School of Public Health, Nanchang University, Nanchang 330006, P. R. China. ${ }^{2}$ Department of Clinical Laboratory Medicine, Shanghai Pulmonary Hospital, Tongji University School of Medicine, Shanghai 200082, P. R. China. ${ }^{3}$ Department of Laboratory Medicine, the First Affiliated Hospital of Wenzhou Medical University, Wenzhou 325000, P. R. China. ${ }^{4}$ Department of Respiratory Medicine, the First Affiliated Hospital of Wenzhou Medical University, Wenzhou 325000, P. R. China. ${ }^{5}$ Shanghai Key Laboratory of Tuberculosis, Shanghai Pulmonary Hospital, Tongji University School of Medicine, Shanghai 200082, P. R. China.

\section{Received: 11 January 2021 Accepted: 21 May 2021}

\section{Published online: 02 June 2021}

\section{References}

1. Shon AS, Bajwa RP, Russo TA. Hypervirulent (hypermucoviscous) Klebsiella pneumoniae: a new and dangerous breed. Virulence. 2013;4(2):107-18. https://doi.org/10.4161/viru.22718

2. P, N., C. G, and N. T. The real threat of Klebsiella pneumoniae carbapenemase-producing bacteria. Lancet Infect Dis. 2009;9(4):228-36. https://doi.org/10.1016/S1473-3099(09)70054-4.

3. Struve C, et al. Mapping the Evolution of Hypervirulent Klebsiella pneumoniae. mBio. 2015;6(4).

4. Zhang Y, et al. Epidemiology of Carbapenem-Resistant Enterobacteriaceae Infections: Report from the China CRE Network. Antimicrob Agents Chemother. 2018:62(2)

5. Zhao Z, et al. Evaluation of automated systems for aminoglycosides and fluoroquinolones susceptibility testing for Carbapenem-resistant Enterobacteriaceae. Antimicrob Resist Infect Control. 2017;6(1).

6. Ni W, Wei C, Zhou C, Zhao J, Liang B, Cui J, et al. Tigecycline-amikacin combination effectively suppresses the selection of resistance in clinical isolates of KPC-producing Klebsiella pneumoniae. Front Microbiol. 2016;7. https://doi.org/10.3389/fmicb.2016.01304.

7. HJ M, et al. Treatment Options for Carbapenem-Resistant Enterobacteriaceae Infections. Open Forum Infect Dis. 2015;2(2):ofv050.

8. Fabrega $A$, et al. Mechanism of action of and resistance to quinolones. Microb Biotechnol. 2009;2(1):40-61. https://doi.org/10.1111/j.1751-7915.2008. 00063.x.

9. Fuzi M, Szabo D, Csercsik R. Double-Serine Fluoroquinolone Resistance Mutations Advance Major International Clones and Lineages of Various Multi-Drug Resistant Bacteria. Front Microbiol. 2017;8:2261. https://doi.org/1 0.3389/fmicb.2017.02261

10. IW F, et al. Ciprofloxacin concentrations in bone and muscle after oral dosing. Antimicrob Agents Chemother. 1986:29(3):405-8.

11. Vardakas KZ, Tansarli GS, Rafailidis PI, Falagas ME. Carbapenems versus alternative antibiotics for the treatment of bacteraemia due to Enterobacteriaceae producing extended-spectrum beta-lactamases: a systematic review and meta-analysis. J Antimicrob Chemother. 2012;67(12): 2793-803. https://doi.org/10.1093/jac/dks301.

12. Hsu A, Tamma P. Treatment of multidrug-resistant gram-negative infections in children. Clin Infect Dis. 2014;58(10):1439-48. https://doi.org/10.1093/cid/ ciu069.

13. Muggeo A, Guillard T, Klein F, Reffuveille F, François C, Babosan A, et al. Spread of Klebsiella pneumoniae ST395 non-susceptible to carbapenems and resistant to fluoroquinolones in north-eastern France. J Glob Antimicrob Resist. 2018;13:98-103. https://doi.org/10.1016/j.jgar.2017.10.023.
14. Chattaway MA, et al. Fluoroquinolone-resistant enteric Bacteria in subSaharan Africa: clones, Implications and Research Needs. Front Microbiol. 2016;7:558.

15. Wen $Y$, Pu X, Zheng W, Hu G. High prevalence of plasmid-mediated quinolone resistance and IncQ plasmids carrying qnrS2 gene in Bacteria from Rivers near hospitals and aquaculture in China. PLoS One. 2016;11(7): e0159418. https://doi.org/10.1371/journal.pone.0159418.

16. DC H. Mechanisms of fluoroquinolone resistance. Drug Resist Updat. 1999; 2(1):38-55.

17. A, O., H. M, and K. E. Prevalence of plasmid-mediated multidrug resistance determinants in fluoroquinolone-resistant bacteria isolated from sewage and surface water. Environ Sci Pollut Res Int. 2016;23(11):10818-31.

18. Park YJ, Yu JK, Kim SY, Lee S, Jeong SH. Prevalence and characteristics of qur determinants and aac(6')-lb-cr among ciprofloxacin-susceptible isolates of Klebsiella pneumoniae in Korea. J Antimicrob Chemother. 2010;65(9): 2041-3. https://doi.org/10.1093/jac/dkq258.

19. Yang H, Duan G, Zhu J, Zhang W, Xi Y, Fan Q. Prevalence and characterisation of plasmid-mediated quinolone resistance and mutations in the gyrase and topoisomerase IV genes among Shigella isolates from Henan, China, between 2001 and 2008. Int J Antimicrob Agents. 2013;42(2): 173-7. https://doi.org/10.1016/j.ijantimicag.2013.04.026.

20. Briales A, Rodríguez-Martínez JM, Velasco C, de Alba PD, Rodríguez-Baño J, Martínez-Martínez L, et al. Prevalence of plasmid-mediated quinolone resistance determinants qur and aac(6')-lb-cr in Escherichia coli and Klebsiella pneumoniae producing extended-spectrum beta-lactamases in Spain. Int J Antimicrob Agents. 2012;39(5):431-4. https://doi.org/10.1016/j.ija ntimicag.2011.12.009.

21. Yang $H$, Chen $H$, Yang Q, Chen M, Wang $H$. High prevalence of plasmidmediated quinolone resistance genes qnr and aac $\left(6^{6}\right)-\mathrm{lb}-\mathrm{Cr}$ in clinical isolates of Enterobacteriaceae from nine teaching hospitals in China. Antimicrob Agents Chemother. 2008;52(12):4268-73. https://doi.org/10.1128/AAC.00830-08.

22. Piekarska K, Wołkowicz T, Zacharczuk K, Rzeczkowska M, Chróst A, Bareja E, et al. Co-existence of plasmid-mediated quinolone resistance determinants and mutations in gyrA and parC among fluoroquinolone-resistant clinical Enterobacteriaceae isolated in a tertiary hospital in Warsaw, Poland. Int J Antimicrob Agents. 2015;45(3):238-43. https://doi.org/10.1016/j.ijantimicag.2 014.09.019.

23. CLSI, Performance Standards for Antimicrobial Susceptibility Testing. 28th ed, 2018CLSI. CLSI supplement M100.Wayne (PA:Clinical and Laboratory Standard Institute;2018. 2018: p. 320.)

24. JM, R.-M, et al. Correlation of quinolone resistance levels and differences in basal and quinolone-induced expression from three qnrA-containing plasmids. Clin Microbiol Infect. 2006;12(5):440-5.

25. Wang M, Tran JH, Jacoby GA, Zhang Y, Wang F, Hooper DC. Plasmidmediated quinolone resistance in clinical isolates of Escherichia coli from Shanghai, China. Antimicrob Agents Chemother. 2003;47(7):2242-8. https:// doi.org/10.1128/AAC.47.7.2242-2248.2003.

26. J, X, et al. Klebsiella pneumoniae clonal Spread of 165 rRNA Methyltransferase-Producing ST37 with High Prevalence of ESBLs from Companion Animals in China. Front Microbiol. 2017;8:529.

27. DD W, et al. Emergence of KPC-producing Klebsiella pneumoniae hypervirulent clone of capsular serotype K1 that belongs to sequence type 11 in mainland China. Diagn Microbiol Infect Dis. 2016:85(2):192-4.

28. Diancourt L, Passet V, Verhoef J, Grimont PAD, Brisse S. Multilocus sequence typing of Klebsiella pneumoniae nosocomial isolates. J Clin Microbiol. 2005; 43(8):4178-82. https://doi.org/10.1128/JCM.43.8.4178-4182.2005.

29. Nagasaka Y, Kimura K, Yamada K, Wachino Jl, Jin W, Notake S, et al. Genetic profiles of fluoroquinolone-NonsusceptibleKlebsiella pneumoniaeAmong Cephalosporin-ResistantK. Pneumoniae. Microb Drug Resist. 2015;21(2):22433. https://doi.org/10.1089/mdr.2014.0150.

30. Blondeau JM. Fluoroquinolones: mechanism of action, classification, and development of resistance. Surv Ophthalmol. 2004;49(2):S73-8. https://doi. org/10.1016/j.survophthal.2004.01.005.

31. M, G, et al. Ciprofloxacin-resistant Haemophilus influenzae strains possess mutations in analogous positions of GyrA and ParC. Antimicrob Agents Chemother. 1996;40(7):1741-4.

32. J, V, et al. Association between double mutation in gyrA gene of ciprofloxacin-resistant clinical isolates of Escherichia coli and MICs. Antimicrob Agents Chemother. 1994;38(10):2477-9.

33. Voulgari E, Zarkotou O, Ranellou K, Karageorgopoulos DE, Vrioni G, Mamali $\checkmark$, et al. Outbreak of OXA-48 carbapenemase-producing Klebsiella 
pneumoniae in Greece involving an ST11 clone. J Antimicrob Chemother. 2012;68(1):84-8. https://doi.org/10.1093/jac/dks356.

34. Liao W, Liu Y, Zhang W. Virulence evolution, molecular mechanisms of resistance and prevalence of ST11 carbapenem-resistant Klebsiella pneumoniae in China: a review over the last 10 years. J Glob Antimicrob Resist. 2020;23:174-80. https://doi.org/10.1016/j.jgar.2020.09.004.

35. Zeng $L$, et al. The determination of gyrA and parC mutations and the prevalence of plasmid-mediated quinolone resistance genes in carbapenem resistant Klebsiella pneumonia ST11 and ST76 strains isolated from patients in Heilongjiang Province, China. Infect Genet Evol. 2020;82:104319.

36. Zhao X, Xu X, Zhu D, Ye X, Wang M. Decreased quinolone susceptibility in high percentage of Enterobacter cloacae clinical isolates caused only by Qnr determinants. Diagn Microbiol Infect Dis. 2010;67(1):110-3. https://doi. org/10.1016/j.diagmicrobio.2009.12.018.

\section{Publisher's Note}

Springer Nature remains neutral with regard to jurisdictional claims in published maps and institutional affiliations.

Ready to submit your research? Choose BMC and benefit from:

- fast, convenient online submission

- thorough peer review by experienced researchers in your field

- rapid publication on acceptance

- support for research data, including large and complex data types

- gold Open Access which fosters wider collaboration and increased citations

- maximum visibility for your research: over $100 \mathrm{M}$ website views per year

At BMC, research is always in progress.

Learn more biomedcentral.com/submissions 